\title{
1. Intellectual property as a complex adaptive system
}

\section{Anselm Kamperman Sanders and Anke Moerland}

This chapter discusses the common angle to all contributions of this book. All share the understanding that intellectual property (IP) must be treated as a complex adaptive system (CAS). We examine IP structures, collaborations, distribution models and law-making in order to show the complex and interdependent relationships in which IP operates. This focus on IP as a complex adaptive system is necessary in order to address the problem of the "Valley of Death": many inventions developed in the laboratory or research institutes are not brought to the market, arguably due to the complex relationships that lie at the heart of innovation. We discuss complex adaptive systems as applied to IP and the phenomenon of the "Valley of Death" as the embedding of the following chapters.

\subsection{COMPLEX ADAPTIVE SYSTEMS}

Mitchell has defined CAS as "a system in which large networks of components with no central control and simple rules of operation give rise to complex collective behavior, sophisticated information processing, and adaptation via learning or evolution". ${ }^{1}$ In other words, these systems consist of 1) many heterogeneous agents who interact with and learn from each other. This 2) leads to adaptation over time, in order to improve their performance. ${ }^{2}$ The interaction and adaptation 3) leads to self-organized collective behaviour which 4) is not controlled through any external party. ${ }^{3}$

We call a system complex when understanding the behaviour of each agent individually does not mean one understands the system as a whole. ${ }^{4}$ That is

Melanie Mitchell, Complexity: A Guided Tour (OUP 2009), 13.

John H. Holland, "Complex Adaptive Systems" [1992] 121 Daedalus 1, 18.

Mitchell (n 1), 12-13.

4 John H. Miller and Scott E. Page, Complex Adaptive Systems: An Introduction to Computational Models of Social Life (Princeton University Press 2007), 3. 
because the system exhibits properties and behaviours that are different from those of their underlying parts. The aggregated interactions of system components produce entirely new patterns and behaviours. The opposite of complex are linear systems, in which "the relationship between cause and effect is smooth and proportionate". 5

Obvious examples of complex adaptive systems are biological species, economies or the brain. ${ }^{6}$ But interestingly, it has also been applied to areas of law, such as international investment $\mathrm{law}^{7}$ and international environmental law, ${ }^{8}$ as well as to the diffusion of innovation. ${ }^{9}$ Another example of complex interactions is the burst of the Internet bubble, leading to an increase in ICT connectivity, enabling African entrepreneurs to overcome developmental constraints and tailor their fashion designs to global tastes, sizes and markets.

We apply this framework to intellectual property law because we believe that it displays CAS properties. The interaction between various actors in the IP system are nonlinear, uncertain, and unpredictable. Societal demands on the innovation ecosystem have fundamentally altered the perception of intellectual property from a mere legal title that confers a right to exclude others, to a complex adaptive system. In this new reality, IP functions as a business tool for value creation, a vehicle for investment and a relationship between right holders, users and society.

The complexity of the IP system can be seen in terms of 1) diverse actors (private, commercial and non-commercial); 2) multifaceted subject matter in material or digital form; 3 ) governance by inter-sectoral organizations, institutions and public authorities; 4) overlapping and multi-layered adjudication in commercial, administrative and criminal matters at national, regional and international level, and 5) all of these interacting within a broader economic, legal, societal and political system. In addition, the system generates interconnections and feedback loops throughout its lifecycle stages, for example works produced and marketed will not only generate income, but also information on consumer preferences. All of this leads to non-linear effects on innovation at global and local level.

$5 \quad$ See Everett M. Rogers, Una E. Medina, Mario A. Rivera and Cody J. Wiley, "Complex Adaptive Systems and the Diffusion of Innovations" [2005] 10 The Innovation Journal: The Public Sector Innovation Journal 3.

6 For a good overview of literature dealing with complex adaptive systems, see Rakhyun E. Kim and Brandan Mackey, "International Environmental Law As a Complex Adaptive System" [2014] 14 International Environmental Agreements 1, 6.

7 Joost Pauwelyn, "At the Edge of Chaos? Foreign Investment Law as A Complex Adaptive System, How It Emerged And How It Can Be Reformed" (2014)<https://ssrn .com/abstract=2271869> (accessed 10 March 2021).

8 See Kim and Mackey (n 6).

$9 \quad$ See Rogers, Medina, Rivera and Wiley (n 5), 3. 


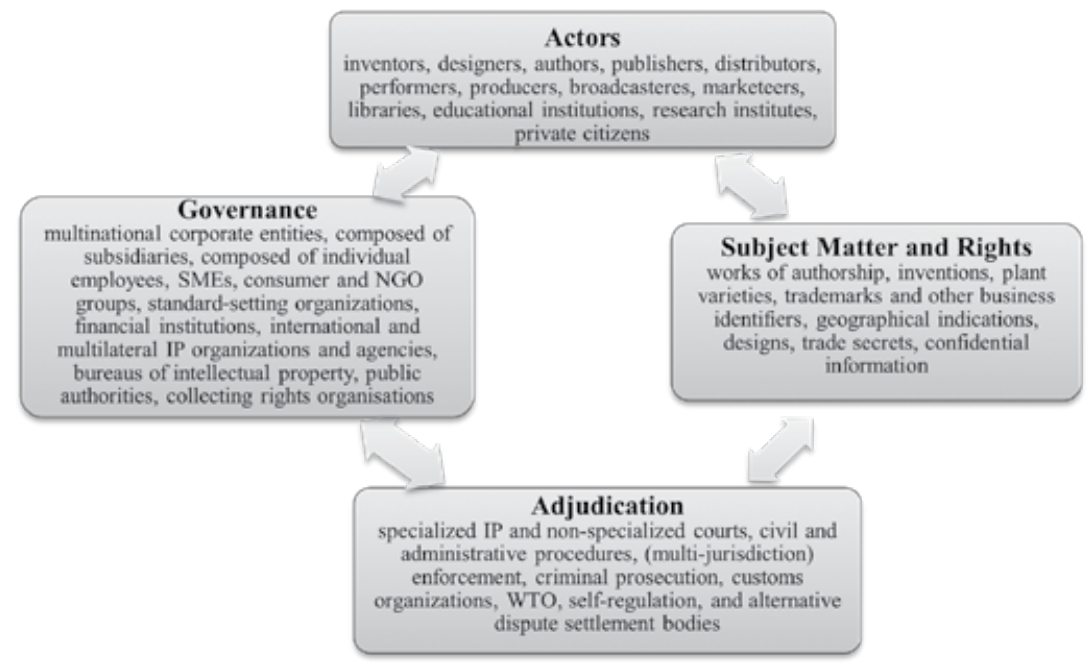

Source: Authors.

Figure 1.1 Interaction between actors, systems and organizations

IP as CAS requires an architecture capable of accommodating new technologies, cultural and artistic expressions and contribute to innovation in a way that is acceptable and beneficial to society. It is clear that the hitherto prevailing reductionist view of IP as a mere legal title does not adequately address its role. This is particularly visible when studying the role of IP in the context of the Valley of Death.

Table 1.1 Functions of IP as a complex adaptive system

\begin{tabular}{lll}
\hline a relationship for & a business tool for & an investment vehicle for \\
\hline B2B, and public-private & Value creation; & Merger and acquisition; \\
partnerships; & Creating a revenue stream; & Due diligence; \\
Investors and financial institutions; & Dissemination of knowledge; & Collateral and funding; \\
Technology transfer; & Freedom to operate; & Taxation; \\
Assignment, licensing and & Enforcement & Accounting \\
franchising; & & \\
Open access and creative commons & & \\
\hline
\end{tabular}

Source: Authors. 


\subsection{THE VALLEY OF DEATH}

The term "Valley of Death" is used to describe the instance where progress in science fails to provide the basis of a commercially successful business or product. It occurs at a time when the baton of basic research is handed over to a more applied scientist or even commercial actor. It is at that point that funding necessary to move towards a commercially viable product becomes inconsistent at best. This is problematic as even more losses will have to be incurred before a product or business can be launched. The costs incurred prior to break-even into profit involve: research, technology transfer, proof of concept, prototype design, up scaling, preclinical development (for pharmaceuticals), ${ }^{10}$ product launch and early commercialization. So even if there is a working prototype for a product or service, it does not translate into a marketable product or business.

It has long been recognized that developed economies suffer from the paradox that good science is not necessarily translated into healthy exploitation. In fact, many products for which there is potential consumer demand do not reach the market at all, or are only later picked up by third parties who do not re-invest in the science base that produced the innovation in the first place. Venture capitalists, angel investors, and private foundation research funds have traditionally been heralded as being able to provide the bridge. With the economic crisis resulting in risk-averse behaviour on the part of the private sector, it will rather be largely up to government to provide funding. Public funding of basic research then extends to prototyping etc., where the aim of such funding is to do more than just produce public domain knowledge.

Also, government has scarce resources and somehow has to decide which technologies deserve to make it out of the valley of death when market pull appears to be insufficient. Public-private partnerships (PPP), therefore, remain indispensable in order to ensure that the bridge is firmly anchored on both sides of the valley. Globalization may in this context have enabled efficient allocation of production and even R\&D across continents; it has not yet resulted in a transparent global market for the transfer of technology. This contribution explores the way in which the valley of death can be overcome through public-private partnerships and other regulatory instruments, while focusing on intellectual property and management thereof in a globalized market.

10 Clinical trials are usually paid for by the pharmaceutical industry. 


\subsubsection{Innovation As a Dynamic Process}

While on the one hand technologies that do not make it out of the valley of death can be said to lack commercial potential, many promising technologies fall by the wayside, or are commercialized later by parties that have not and will not contribute to sustaining the research base responsible for developing them. In fact, a 2013 report by the UK House of Commons science and technology committee expressed concern about the fact that the UK, while producing excellent science is incapable of retaining that technology for domestic business and entrepreneurs. ${ }^{11}$ It is important to realize in this context that incremental product innovation is the main driver for growth in companies. Moving beyond incremental product innovation is much riskier although business model innovation is an area of growth. ${ }^{12}$ Bringing new technologies to market not only requires venture capital investments to bridge the gap between the early-stage proof of concept nature of technology, up-scaling production and the subsequent generation of revenues. Rather, aside from finance, there is a need for the creation and exchange of knowledge and access to trained people and services. In this context it is of importance to realize that innovation is not a linear process, although it is often represented as such. ${ }^{13}$

Rather, innovation is a dynamic process where interdependencies between government, universities and research institutes, venture capitalists, banks and public markets, and large and small businesses create a web of regulatory and fiscal measures, standards, finance, education, information and knowledge exchange and intellectual property.

The resulting picture is far more complex and describes an innovation ecosystem full of interdependencies, but the prime aim is that knowledge and finance can flow in an efficient manner so as to stimulate the commercialization of innovations in products and services. The role of government is to fund universities and public sector research and provide for regulations standards and a fiscal environment conducive to innovation. Universities and public sector research institutions in turn have the primary duty to produce trained graduates, academic output, and intellectual property.

The hot potato is always to what extent universities and public sector research institutions should attract finance, and whether this finance should go

11 House of Commons, Science and Technology Committee, Bridging the Valley of Death: Improving the Commercialisation of Research, (2013, HC 348, Stationary Office).

12 See GE Global Innovation Barometer, <www.ge.com/innovation-barometer/> (accessed 10 March 2021).

13 Christine Greenhalgh and Marc Rogers, Innovation, Intellectual Property, and Economic Growth (Princeton University Press 2010). 
towards the primary processes described above, or whether it should rather be spent on applied realization and commercialization of knowledge. Apart from government, large firms, seed and venture capital organizations, banks and public markets are the sources of such funding. A go-between is often necessary to generate an index of commercial possibilities of the research output generated by universities and public sector research institutions. The index of commercial possibilities is often created by university spinouts, start-ups and small and medium-sized enterprises (SMEs). The importance of these intermediaries cannot be overstated, as research results by themselves do not translate into commercially viable products or processes. Rather, one needs entrepreneurial university alumni to work in the spinouts, start-ups and SMEs.

In times of economic crisis, finance is becoming an issue, and the withdrawal of traditional investors in innovation, such as insurers and pension funds, has prompted a call for more venture capital, access to bond markets for innovative SMEs, bank loans, and government grants. It is quite remarkable to see in the UK House of Commons science and technology committee that government, rather than trying to pick winners to sponsor, should incentivize innovation through public procurement of innovative products and services, especially where SMEs are concerned. In the following sections, we will touch upon all aspects that are of importance to innovation, while homing in on intellectual property and knowledge transfer in various sectors of technology.

\subsubsection{The Role of Intellectual Property}

When reading the UK House of Commons science and technology committee report, one can only conclude that intellectual property plays a modest, but important role in innovation. When considering bridging the valley of death, however, it is clear that intellectual property is a key element in the transfer of technology: knowledge disclosed in patent documents and copyright works serves to disseminate the state of the art through scientific publications. Furthermore, intellectual property facilitates the assignment or licensing of intellectual and industrial creativity as if one were dealing with a limited resource. Intellectual property rights create scarcity in relation to certain innovative ideas that, without their legal recognition as property, rights could be freely copied.

The nature of a mere idea is that there is no natural scarcity in it once it has entered the public domain. Without the legal proprietary fence of intellectual property, intellectual and industrial creativity amount to mere ideas that bear all the characteristics of public goods. Fair competition in a free-market economy can be characterized by the fact that demand and supply determine the price of a product. This basic economic rationale that underlies a market economy requires that, as a matter of principle, there is freedom for compet- 
itors to copy and build upon the achievements of other market participants. Intellectual property rights can be justified as exclusive rights in relation to intellectual and industrial creativity only on the basis of the fact that they address specific instances of market failure in a market for original expressive works. Without intellectual property rights, there would be no market for industrial and intellectual creativity.

In order to ensure a transparent and diversified market for products or services, the protection of trademarks or other badges of trade against confusing uses can equally be justified. The patent monopoly can be justified in the free-market economy as it does not take away from the public something that existed before, but rather creates a competitive market in disclosed and novel inventive ideas themselves. In all instances, public welfare is increased as more creative works will be produced, market transparency facilitates consumer choice, and technology can be incorporated in products, while disclosure opens claimed inventions up to scrutiny for improvement or alternatives. In all these instances, intellectual property rights govern competitive relationships in commerce, although copyright protection in relation to original expressions in works of authorship (art, literature and science, etc.) can also extend to the private sphere.

When considering innovation, intellectual property is a tool that can be used to create revenue streams from intellectual and industrial creativity. In addition to market positions, intellectual property also serves to disseminate knowledge, transfer technology, acquire funding, and create transactional collateral. Although we have seen that the innovation process is not linear, it is important to realize that different intellectual property rights feature more prominently at different stages of product development. Confidentiality and patent applications typically dominate in the early research stages. Applying for design rights and utility models becomes relevant as part of the proof of concept and when prototypes are being developed. This bundle of intellectual property rights and the related know-how acquired prior to the up-scaling of production will be of relevance to the initial technology transfer to a spinout or start-up. Together with a business plan and related trade secrets, they serve to convince investors that there is sufficient collateral to provide funding to make it to market. It is at this point that trademarks need to be applied for to serve as business identifiers. When combined with an effective marketing and advertising strategy, they can facilitate purchasing decisions.

What is evident is that from the point of commercial strategy, an immense amount of planning must take place to obtain intellectual property rights and utilize them in a strategic fashion. Start-ups and SMEs, however, lack the means and capacity to do this properly. When it comes to actual enforcement of intellectual property rights, the picture is even bleaker. Enforcement through the courts is often incredibly expensive. This is why, in a number of 
jurisdictions, courts specializing in intellectual property disputes are set up. Mediation services, such as those offered by the WIPO Dispute Resolution Center in respect of domain names, have already proven their worth as low-cost alternatives to court action.

\subsubsection{The Role of Government}

It is evident that government, through legislation and norm setting, is in a position to provide a stable environment that minimizes the burden of entrepreneurs. When it comes to innovation policy however, government can be a driving force through public procurement of new technologies, but also through standard-setting. Government-backed standards or private standards can play a vital role in kickstarting the penetration of new technologies in the marketplace. Prime examples here are telecommunications standards or other standards in the ICT sector. Government can drive policy, or through prudent monitoring by competition authorities allow private parties to formulate standards involving intellectual property on the basis of fair reasonable and non-discriminatory licensing terms.

Patent offices as agencies of the administration have a positive duty to ensure that technical information contained in patent documents is publicly accessible. It is increasingly clear that classification schemes enabling users to find specific technologies have to be continuously updated. The field of sustainable technologies, for example the United Nations Framework Convention on Climate Change (UNFCCC) and the intergovernmental panel on climate change, produced technological guidelines in cooperation with the European Patent Office to facilitate this access. ${ }^{14}$ The new classification system, the so-called "Y-tag" makes it possible to identify a number of climate change mitigation technologies, most notably: 1) in buildings including the residential sector; 2) greenhouse gases capture and storage; 3 ) in energy generation, transmission and distribution; 4) in the transportation of goods and persons; and 5) smart grid technologies.

International organizations such as the World Intellectual Property Organization (WIPO) have also launched an initiative coinciding with the UNFCCC entitled "WIPO Green", ${ }^{15}$ which is rather misleadingly presented as a technology marketplace. It is, however, a networking effort to match owners of intellectual property with providers of consultancy, training and

14 See European Patent Office, The EPO and the UNFCCC, <www.epo.org/clean -energy> (accessed 1 March 2021).

15 See World Intellectual Property Organization, WIPO GREEN - The Marketplace for Sustainable Technology, <www.wipo.int/green> (accessed 1 March 2021). 
financial support. The question remains whether government should do more to ensure that such publicly accessible information can be used in spin-off or incubator facilities for the purpose of testing their practical and commercial viability. The setup of incubators providing large-scale test and experimental production facilities could very well be an area where public-private partnerships can truly flourish. Another area for government intervention lies in the option to open up terms of a licence for inspection by the public when these are registered at a patent office. This is of special relevance to standard setting efforts through public or private initiatives. Commodity pricing of IPRs after all requires transparency.

\subsubsection{The Go-Between}

Universities and public research institutes have traditionally not been engaged in readying their research output for commercial exploitation. This is exacerbated by the fact that academic careers are defined by publications in academic peer-reviewed journals. Even now that patterns are commonly valued as part of the research output, the incentive for the individual academic to go beyond the presentation of the invention in the patent document towards commercialization is only there if the inventor can somehow reap the monetary rewards of his or her invention. Incentivizing researchers to engage with industry is a known problem that is not easily solved. The incentive structures of universities and industry to a certain extent must be different. Universities and research institutes are there to produce knowledge through teaching and research in an open academic discourse. Industry needs to attract capital and manage knowledge for profit in a proprietary, often-confidential, competitive setting. It is therefore the interface where the two paradigms must somehow meet and work together.

Furthermore, where the ownership position of a patent is defined by an employer-employee relationship, as is the case in many jurisdictions, the interests of the University and the individual researcher-employee require alignment prior to engagement with industry. A sensible distribution of proceeds and royalty income along a one-third, one-third, one-third matrix has become best practice in this context. The relative success of the Bayh-Dole $\mathrm{Act}^{16}$ in the United States of America in the promotion of technology transfer has prompted many countries to follow this model.

Still, there is a lot of variation in the implementation. In the USA, the Stevenson-Wydler Technology Innovation Act, §15 USC 3710c(b), sets

16 Bayh-Dole Act of December 12, 1980 (P.L. 96-517, Patent and Trademark Act Amendments of 1980). 
various milestones for the reward of the researcher-employee, with a minimum at US\$2,000 for commercialization, then a further entitlement with a minimum of 15 per cent of the net income to a maximum of US $\$ 150 \mathrm{k}$ per year. In Canada, chapters 1 to 11 of the Award Plan for Inventors and Innovation Policy set the minimum for US $\$ 1,000$ for commercialization, then a minimum of 50 per cent of the net income to a maximum of 35 per cent, but not more than the highest annual wage. In the United Kingdom, the Department of Health NHS Policy on IPRs indicates that the share of income to the inventors is mandatory. There is a recommendation for a fixed 30 per cent share of the income (unlimited), or a sliding scale for 75 per cent up to US $\$ 100 \mathrm{k}, 50$ per cent of the next US $\$ 200 \mathrm{k}$, and 25 per cent of any higher sum. In Denmark, on the other hand, the Danish Act on Inventions at Public Institutions merely indicates that the share of income to the inventors is obligatory, but no limit is specified. In Singapore, the national agency for science technology and research has specified milestones for the reward of the researcher-employee in its so-called A*STAR Policy on IP but the revenues to the inventor are fixed at 35 per cent of the income. In the Netherlands finally, Article 12(3),(6) Rijksoctrooiwet 1995 indicates that a reasonable royalty is mandatory, but there is no indication on the way it is to be calculated. The "Innovation Charter" of Cooperating Dutch Universities (VSNU) the Medical Centers (NFU) and the largest employers' association (VNO-NCW) indicates that the maximum amount is EUR2.200 per annum, a norm that is enshrined in the collective labour agreement of Research Hospitals.

The 2002 EU Commission communication "Innovation in a knowledgedriven economy" ${ }^{17}$ called upon Member States of the Union to adopt a regulatory framework conducive to innovation by: 1) adapting the rules for the diffusion of research results from publicly funded research (licensing, access to foreground knowledge, etc.); 2) encouraging exploitation and transfer of results so as to foster innovation; and 3) putting in place fiscal measures, in accordance with Articles 87 and 88 of the Treaty, to encourage private investment in research and innovation and employment of researchers by the private sector. The Horizon 2020 initiative went further, offering rounds for tenders between 2014 and 2020 for R\&D projects, inter alia, those aiming to bridge the valley of death. The EIPIN Innovation Society project has been one of the projects financed under this funding scheme.

17 On innovation policy in Europe, see European Parliament, Innovation Policy, $<$ www.europarl.europa.eu/factsheets/en/sheet/67/innovation-policy> (accessed 9 March 2021). 
Key in the finding of R\&D at universities and research institutes is the obligation to commercialize funded research. ${ }^{18}$ In many cases, intermediaries or incubator facilities are crucial to do this. ${ }^{19}$ Incubator facilities allow university researchers to interact with business and vice versa allow start-ups and SMEs to access large-scale research and production facilities necessary to test prototypes and explore the upscaling of production of likely successful commercial products or services. The incubator serves as a shop window for ongoing research and development from the early to more mature phases. Large corporations interested in open innovation may also find using these facilities useful to scout the innovation landscape. It is in relation to these types of science parks that governmental regulation, tax incentives and a clear intellectual property regime can be welded together in a coherent package.

As far as intellectual property rights are concerned, an open innovation model is key to the success of such facilities. Open innovation in this context does not mean that intellectual property is not claimed, or somehow free-quite the contrary. Users of the facility are interested in participating collectively as far as the facility itself is concerned, equally they are interested in taking out proprietary rights that secure an exclusive market position in respect of a commercial product or service. Collaborations in a shared facility should adhere to some ground rules, where clear choices have to be made in terms of what IP to share, what IP to license in or out, what IP to hold proprietary, and what IP to pool or standardize. Up-scaler, incubator, or large-scale cloud-computing facilities require "collaborative IP" when offering enabling technologies, production equipment and test facilities. Users of the facility should be able to freely "move" their proprietary IP in and out of the facility but should be compelled to make any improvement to the facility that results from the work undertaken there available to the facility under a reasonable license at a minimum. The more collaborative IP can then be offered on a subscription rate, the lower the threshold for SMEs will be to use the facility.

\subsubsection{Valuation}

Intellectual property rights are therefore interwoven with each stage of the innovation process. Crucial in all instances is the awareness of intellectual property rights of others that define the freedom to operate, the technology, goods or services that have to be covered by one's own intellectual property,

18 Mark Harvey and Andrew McMeekin, Public or Private Economies of Knowledge? Turbulence in the Biological Sciences (Edward Elgar Publishing 2007).

19 Graham Richards, Spin-Outs - Creating Business from University Intellectual Property (Harriman House 2009). 
the robustness of one's own and others' rights and the enforceability of one's rights in the marketplace. The value of intellectual property is therefore predominantly strategic in nature, as the actual monetary value is difficult to gauge independently from a product or service offered in the marketplace. There has however been an upward trend in the share of intangible assets in company valuation from a mere 17 per cent in 1975 to a stable 80 per cent from 2015 onward. COVID-19 has even accelerated this trend and intangible assets now command over 90 per cent of the S\&P500 market value. ${ }^{20}$ The number of patent applications to the European Patent Office keep rising as well, ${ }^{21}$ and a joint 2021 firm-level analysis by the European Patent Office and the European Intellectual Property Office confirms that "firms that own IPRs generate 20 per cent higher revenues per employee than their counterparts without an IP portfolio". ${ }^{22}$ It is important to realize, as the study confirms, that these gains are linked to bundles of trade marks and designs, or combinations of patent, trade marks and designs.

The common complaint of industry is, therefore, that universities and research institutes often have an unrealistic and inflated idea of the value of their IP. Accounting standards ${ }^{23}$ are in this respect not helpful to establish market prices for intellectual property assets that universities and research institutes wish to spin out. If, however, one needs a price, the only thing one can do is adhere to a certified method of calculating the value of the intellectual property asset in question. The German Institute for Standardization (DIN) General Principles of Proper Patent Valuation ${ }^{24}$ and the American Society of Appraisers (ASA) Business Valuation Standards, ${ }^{25}$ for example, employ

20 See the Ocean Tomo, Intangible Asset Market Value Study 2020, available upon request at <www.oceantomo.com/intangible-asset-market-value-study $>$ (accessed 9 March 2021).

21 See European Patent Office, Patent Statistics, <www.epo.org/about-us/annual -reports-statistics/statistics.html $>$ (accessed 9 March 2021).

22 EPO and EUIPO, Intellectual Property Rights and Firm Performance in the European Union, Firm-level analysis report (February 2021), $<\mathrm{http}: /$ documents.epo .org/projects/babylon/eponet.nsf/0/7120D0280636B3E6C1258673004A8698/\$File/ipr _performance_study_en.pdf $>$ (accessed 9 March 2021).

${ }_{23}$ International Financial Reporting Standards (IFRS) and U.S. General Accepted Accounting Principles (GAAP) are the two most important standards. The EU obliges the use of IFRS since 2005, following Regulation (EC) No 1606/2002 of the European Parliament and of the Council of 19 July 2002 on the application of international accounting standards, whereas the USA may permit IFRS as an alternative to GAAP from 2014 onward.

24 DIN Technical Rule PAS 1070, General Principles of Proper Patent Valuation 2007-02 (Beuth Verlag).

25 American Society of Appraisers, ASA Business Valuation Standards, BVS-IX, $<$ www.appraisers.org/docs/default-source/default-document-library/bv-standards.pdf $>$ 
similar valuation methods. However, even though the factors may be very similar, the outcome may vary significantly. In view of the fact that intellectual property rights are territorial in nature, the value of an intellectual property asset is determined in each instance by national factors and by national valuation methods. Until now, attempts to arrive at an internationally accepted ISO standard for the valuation of patents have been unsuccessful, although there is a standard for brand valuation, namely ISO 10668 for Monetary Brand Valuation of 2010, which encompasses trademarks and other intellectual property assets that are marketing-related, such as names, terms, and logos, etc.

The American ASA Business Valuation Standard for Intangible Asset Valuation is a comprehensive method and deals with the valuation factors to be considered in valuing four types of intellectual property: patents, trade secrets, trademarks and copyright. Income, market, and cost-based approaches must be considered against a number of valuation factors dealing with the legal rights in question:

\section{Valuation methodology}

In valuing an intangible asset, the appraiser should consider appropriate approaches and methods.

Approaches that should be considered in valuing intangible assets are as follows:

A. Income Approach.

1. The appraiser should identify the economic benefits that are reasonably attributable to the subject intangible asset, and the risks associated with realizing those benefits.

2. The appraiser should consider the economic benefit provided by the amortization of the asset's value for income tax purposes, where applicable.

3. The appraiser should consider whether the economic life of the intangible asset is different from its legal or regulatory life.

B. Market Approach. The appraiser should consider relevant differences between the subject and guideline assets as well as respective market conditions.

C. Cost Approach. The appraiser should consider direct and indirect costs associated with reproduction or replacement, as the case may be, as well as any loss of value due to functional or economic obsolescence, or reduced life expectancy.

\section{Factors}

In valuing an intangible asset, the appraiser should consider:

A. The bundle of legal rights, protections and limitations pertaining to the intangible asset to be valued.

B. The history of the intangible asset.

C. The intangible asset's expected remaining economic (useful) and legal life.

(accessed 9 March 2021); and also see Financial Accounting Standards Board, Intangibles - Goodwill and Other [...] - Extending the Private Company Accounting Alternatives on Goodwill and Certain Identifiable Intangible Assets to Not-for-Profit Entities (FASB 2019), <www.fasb.org/jsp/FASB/Document_C/DocumentPage\&cid= $1176172314448>$ (accessed 9 March 2021). 
D. The economic benefits, direct or indirect, that the intangible asset is expected to provide to its owner during the asset's life.

E. Previous or existing litigation involving the intangible asset.

F. The distinction between an undivided interest and a fractional interest in the intangible asset resulting from, e.g., shared ownership or a licensing agreement.

G. The feasibility and character of potential commercial exploitation of the intangible asset.

H. Additional factors relating to the specific type of intangible asset to be valued, as appropriate.

In case of patents, these considerations should reflect the scope of protection and the jurisdictional coverage, whether there is an invent-around alternative to the invention, possible risks of exploitation such as invalidity and infringement, and to what extent the scope of disclosure may result in reverse-engineering by competitors. For a patent portfolio, synergies must be considered, such as the elimination of blocking patent rights that either reduce the likelihood of infringement of third-party rights, or obtain design freedoms. In this context, patent portfolios may also result in a plurality of products embodying the technology. In case of trade secrets, one has to consider the effectiveness of all precautions put in place to ensure nondisclosure. In addition, one needs to assess the risk that a third party may be able to develop independently the secret concerned.

Finally, one needs to assess whether there may be a patentable invention, and if so, whether the costs saved in terms of packaging outweigh the risks associated with disclosure. In case of trademarks, one needs to consider the ability for the market to be extended to related products or services, abandonment through non-use, genericism, and whether there are competing marks. For copyright, finally, one needs to consider whether the right pertains to a derivative or original work and whether there are competing works. Typically for the United States, there is also the issue of registrability and renewals of copyright that is absent in other jurisdictions.

If we then consider the way in which, for example, the value of a patent is to be determined, a number of factors need to be taken into consideration. In terms of the technology itself, the way in which the patent is capable of describing or "capturing" the nature of the invention, influences the patent quality in terms of scope, blocking impact, patent dependency, etc. It is important to realize that technological and legal factors will greatly detract from the value that the patent may have in terms of economic market advantage and commercial success.

If one considers IPR, or legal influences, the patent quality needs to be assessed in terms of: 1) the ability to cover one's own technology and stand up to challenges to the validity of the patent; and 2) the ability to enforce the patent against third parties. The projected value of a patent is negatively 
affected by a combination of factors. These factors all have to be assessed, so as to clarify 1) the status of the patent, 2) the ownership or contractual limitations, 3) patentability or invalidity, 4) the freedom to operate, 5) the scope of the patent, 6) the breadth of the patent and the ability for others to circumvent, and 7) detectability and enforceability. Each of these factors will typically carry a certain weight. Uncertainty about these issues typically leads to up to 80 per cent of the projected value to be discounted.

Issues of circumvention and invent-around can be attributed to a healthy competitive effect of the patent system in terms of the emergence of technological alternatives. Patentability and invalidity may be attributed to policy choices in terms of exclusions in terms of patentable subject matter, or the re-assessment of the novelty and inventive step criteria in opposition or in counterclaim. These are, perhaps, not so problematic, as they are inherent to the system. More problematic are legal uncertainties in relation to ownership and contracts (see above on employer-employee relations) and detectability and enforceability.

Without owning a relevant IP portfolio and a filled war chest it is impossible for research institutes and SMEs to litigate, especially where patent cases are concerned. On the flip-side, non-practicing entities, sometimes referred to as patent trolls, have found a way to create a business out of (threatening) often egregious litigation unless a royalty sum is paid that is just below the tipping point of costs for litigation, which in the USA are on average US\$1 million or more before trial, and US\$2.5 million for a complete defense. ${ }^{26}$ For many companies, especially SMEs and research institutes, it is therefore wiser to avoid the courts. Reducing the cost of litigation, clarifying legal entitlements and promoting transparency in IP transactions, may therefore significantly reduce legal uncertainty, resulting in more realistic expectations on royalty perspectives and calculation of IPR value.

\subsection{COMPLEXITIES REQUIRE ADAPTATION}

When realizing that intellectual property law is part of a complex adaptive system that is interdependent upon various actors from the field of law, policy, finance and science, interventions by the government will always provoke reactions on the market that are difficult, if not impossible to predict. It is the very nature of complex adaptive systems that understanding the behaviour and properties of one agent does not lead to understanding the system as a whole. The constantly evolving nature, creating interactions in various non-linear 
ways, makes predictions of behaviour or the development of markets highly complex.

We found that one of the most important elements in bridging the valley of death is finance. However, financing institutions and actors are only one agent that interacts in the complex system of IP rights. At the same time, intellectual property law and policy play an important role in establishing structural support in the form of reducing legal risks, provide transparency in pricing and establishing the necessary intermediary incubator or up-scaling facilities. The role of government in all of this is to provide clarity in regulatory and contractual frameworks, investment and taxation. Furthermore, it can assist in increasing market transparency in terms of the value of IPRs where the market, by lack of transparently functioning IPR exchanges and trading platforms, is unable or unwilling to do so.

The other chapters of this book compile fascinating insights in several aspects of the valley of death in various sectors, approaching IP as a complex adaptive system. The findings are thought-provoking and may help us to untie some aspects of the complexity, while at the same time not losing sight of the necessities of different markets and legitimate outcomes. Complexities after all require adaptation. 